\title{
AETIOLOGY OF CHOLELITHIASIS IN CHILDHOOD
}

\author{
BY \\ COLIN H. M. WALKER \\ From The Hospital for Sick Children, Great Ormond Street, London
}

(RECEIVED FOR PUBLICATION MARCH 25, 1957)

During the past 10 years case reports of cholelithiasis in childhood and adolescence have appeared fairly regularly and 24 cases under the age of 14 have been described in the English literature during this period. Though stated as being 'infrequent in early life' (Rapoport, 1954), most paediatricians must occasionally have found gall bladder disease to be the cause of hitherto unexplained abdominal pain.

Since 1940, nine cases of proved gall stones have been seen at The Hospital for Sick Children, Great Ormond Street, London. Stones are often associated with haemolytic anaemia, and two of the nine cases were found in association with erythroblastosis foetalis and have been reported by Lightwood and Bodian (1946). Three were found among 42 cases of classical acholuric jaundice, the biliary tracts having been examined in most of the 31 in which splenectomy was performed. Multiple stones were found in one girl who had a history of neonatal sepsis and in whom cavernomatous malformation of the portal vein with portal hypertension was found at the age of 7 years.

There is less awareness of the possibility of stones occurring in the absence of these conditions and, for this reason, the remaining three cases of gall stones of unusual aetiology are described in detail.

The records of 100 random cases of all types of haemolytic anaemia, representing most of the cases seen in this hospital since 1940, have been examined. The relative importance of haemolysis, infection and other aetiological factors is reviewed. The significance of pain as a symptom of gall bladder disease and the absence of splenomegaly in these cases is discussed.

\section{Case Reports}

Case 1. D.C., born August 27, 1952, an only boy of healthy parents, was born at term by spontaneous delivery (birth weight $7 \mathrm{lb} .2 \mathrm{oz}$.). His progress during infancy was uneventful and his developmental milestones were normal. Apart from very occasional vomiting he was well until the age of 3 , when two weeks before admission he began complaining of periumbilical abdominal pain. Vomiting relieved the pain and, at this stage, he was slightly constipated. Four days before admission, he became tired, anorexic and listless and had a bout of severe pain lasting three hours. Two days later he passed a slightly pale stool and again complained of pain. During the week before admission his urine at times appeared darker than usual.

On examination on December 28, 1955, he looked unwell, slightly dehydrated and possibly icteric. He was pale with flushed cheeks and a few scattered recent bruises on the shins were seen. He had minimal faucial congestion. The abdomen was scaphoid and the liver edge was palpable at the umbilicus, smooth, firm and tender. There was a slightly nodular feel at one point along its edge on one occasion during his first admission.

The results of the initial investigations included a haemoglobin which was $85 \%(12.58 \mathrm{~g}$. per $100 \mathrm{ml}$.), the white blood cell count was normal and the sedimentation rate $11 \mathrm{~mm}$. in one hour. The urine showed a slight trace of protein, no deposit and a positive reaction for bile pigments and salts. The total serum bilirubin was 0.7 units per $100 \mathrm{ml}$; the thymol turbidity, 1 unit; Kunkel turbidity, 1 unit; alkaline phosphatase, 26 units per $100 \mathrm{ml}$; t total serum proteins (drop method), $6 \cdot 1 \mathrm{~g}$. per $100 \mathrm{ml}$. with diminished $\gamma$ globulin on electrophoresis. His glucose tolerance curve, blood urea and stool culture were normal. Radiographs of the skull, long bones, chest and abdomen were normal though some opacities on the right side of the abdomen were seen. After further films they were considered to be artefacts.

With bed rest and symptomatic treatment he improved, regaining his appetite and gaining weight within a few days. On January 3, 1956, six days after admission, the urine bile pigments and salts had disappeared and the alkaline phosphatase level on January 10 was 15 units per $100 \mathrm{ml}$. He was discharged home on January $\mathbf{2 0}$ on a reduced fat diet, a provisional diagnosis of infectious hepatitis having been made.

On February 27 he was readmitted after a recurrence of severe abdominal pain, having been well since discharge except for a four-day attack of gastro-enteritis. Again the liver edge was almost down to the umbilicus and the fullness at its edge suggested an enlarged gall bladder. The Fouchet test for bilirubin in the urine was initially negative and became positive three days after admission for five days. The serum bilirubin reached $1 \cdot 2 \mathrm{~g}$. per $100 \mathrm{ml}$. and other blood and urine investigations (including serum cholesterol) showed no significant change. Cholecystography on two occasions showed 
normal gall bladder and biliary duct shadows. No calculi were visualized. As before, the abdominal pains gradually settled and on discharge on April 6 the liver edge was $1-1 \frac{1}{2}$ in. below the costal margin.

On June 18 the boy was readmitted having had a recurrence of symptoms and the liver, having been normal in size during follow-up as an out-patient, had again enlarged to half-way between the costal margin and the umbilicus. He had gained only $8 \mathrm{oz}$. since the previous admission. The liver function tests were as follows : Serum bilirubin (total) less than $0.5 \mathrm{mg}$. per $100 \mathrm{ml}$., alkaline phosphatase 14 units per $100 \mathrm{ml}$., thymol and Kunkel turbidities 9 and 7 units respectively, total serum proteins $5.8 \mathrm{~g}$. per $100 \mathrm{ml}$., the greatest reduction being in globulins, especially $\gamma$ globulin. The red blood cell fragility was normal and the reticulocyte count was $0.8 \%$.

A laparotomy was performed by Mr. H. H. Nixon on July 4 when a cholecystectomy was performed and a liver biopsy was taken. The post-operative course was uneventful and he was discharged symptom-free on the eleventh post-operative day. The turbidity tests were normal before discharge though the $\gamma$ globulin was still reduced on electrophoresis. When seen one month after discharge he was symptom-free though his weight gain was still slow.

Laparotomy material was examined. The gall stone was mainly organic. Cholesterol and bilirubin were detected, but no phosphate, calcium or carbonate. The gall bladder showed myohypertrophy of the bladder wall.

The architecture of the liver and the hepatic cells were normal. There was moderate infiltration of the sinusoidal vessels and to a lesser extent of the portal areas with polymorphonuclear leucocytes, probably an inflammatory sequel to intermittent obstruction of the bile ducts.

Serial sections of the cystic duct showed it to be patent throughout its length and there was no evidence of any stenosis.

Case 2. J.W., born on July 29, 1942, an only girl of healthy parents, was born after a normal pregnancy and labour (birth weight $7 \mathrm{lb}$. $14 \mathrm{oz}$.). Her development was normal during infancy and she had measles, whooping cough and recurrent tonsillitis with cough and vomiting in her early years. Her tonsils and adenoids were removed in 1948 (aged 6 years), but it was not till a year later she attended The Hospital for Sick Children, Great Ormond Street. In May, 1949, she was seen on account of kyphoscoliosis and was given physiotherapy. She began to complain of attacks of fever associated with dysuria, frequency and nocturnal enuresis. She was treated at home successfully with a sulphonamide preparation. In June (one month later) after some physiotherapy the fever, this time of $102^{\circ} \mathrm{F}$., recurred and she developed headache and anorexia. She had pain over the right iliac crest for four days when it suddenly disappeared.

On examination she was found to be in good general condition but had a throat infection. A soft, insignificant cardiac murmur was heard and no other abnormality was found. Radiographs of the spine showed slight scoliosis and although there were a few W.B.C.s and a scanty growth of Esch. coli was obtained from a catheter specimen of urine it was alkaline and contained no protein. She was therefore referred back to her home doctor with recommendations for chemotherapy.

She next attended in October, 1951, with complaints of fatigue, lassitude, night sweats, rare 'bilious attacks' and occasional aching across the shoulders. These had been present intermittently for about two years. Reexamination showed a slightly tender right hypochondrium with a liver edge $\frac{1}{2}$ in. below the costal margin.

The Mantoux test $(1: 100)$ was positive, the E.S.R. was $12 \mathrm{~mm}$. in one hour, the chest radiograph was clear but the spine radiograph showed the persistence of scoliosis and suggested the presence of at least two gall stones. Cholecystography proved that the opacities were within the gall bladder (Fig. 1). Further investigations before cholecystectomy gave the following results: Blood group O Rh positive; $\mathrm{Hb} 96 \%(13.4 \mathrm{~g}$. per $100 \mathrm{ml}$.); R.B.C. count 4.98 million (reticulocytes $0.4 \%$ ); red cells on a blood film appeared normal and red cell fragility was normal; W.B.C. count 6,200 per c.mm. (46\% neutrophils, $54 \%$ lymphocytes); platelet count 277,860 per c.mm.; total serum bilirubin $0.29 \mathrm{mg}$. per $100 \mathrm{ml}$. (all of direct type); blood cholesterol $149 \mathrm{mg}$. per $100 \mathrm{ml}$; urine normal.

Cholecystectomy was performed by Mr. Macnab on November 26, 1951. One month later she was doing well and was discharged from the Surgical Department to continue physiotherapy for poor posture and scoliosis.

Laparotomy material was examimed. The gall stones contained $1.4 \%$ cholesterol and the bilirubin test was strongly positive.

Bile culture was sterile.

The gall bladder was macroscopically and microscopically normal.

Serial sections of the cystic duct showed that there was undoubtedly very severe stenosis of a segment of the cystic duct, but no complete atresia. A lumen, however small in one area, seemed to be present throughout.

Case 3. C.S., born on June 18, 1943, the second child (female) of healthy parents was born spontaneously at term (birth weight $9 \mathrm{lb} .14 \mathrm{oz}$.). The neonatal condition was satisfactory and there was no jaundice. Breast feeding ceased at 2 weeks owing to failure of lactation, but apart from excessive lacrimation of the left eye, her progress was satisfactory until December, 1943. She was then admitted to hospital with a 10-week history of vomiting and pale, hard stools and an eight-week history of jaundice. The urine was bright yellow though this and the jaundice were becoming less intense before admission. The appetite had been good and she was gaining weight. There had been no contact with infectious hepatitis and no source of homologous serum jaundice was found. Her 16-year-old brother was normal. 
On examination she was fretful and febrile (temp. $102^{\circ}$ ). Despite the history she was about $1 \frac{1}{2} \mathrm{lb}$. under her expected weight. She was moderately jaundiced and not obviously anaemic. The abdomen was distended, the liver was two fingerbreadths below the costal margin but the spleen was not felt. There were no other significant findings.

The $\mathrm{Hb}$ was $103 \%$, the W.B.C. count was 13,000 per c.mm. with a normal differential count. No microspherocytes were present. The urine contained bile, and the stool was colourless, dry and crumbly. The total serum bilirubin was $6.2 \mathrm{mg}$. \%, the Takata-Ara reaction was negative and the R.B.C. fragility was normal. A chest radiograph was normal and the Mantoux test $(1: 1,000)$ was negative.

Three days after admission shifting dullness was detected in the abdomen and on December 19, with the temperature, pulse and respiration gradually rising, abdominal paracentesis yielded thick, dark, bile-stained fluid. The treatment to date consisted of sedatives and intramuscular vitamin K. Shortly after the paracentesis her condition deteriorated rapidly and she died the same day.

NeCropsy. There was deep jaundice. The abdomen was distended and thick, purulent, bile-stained fluid was found in the peritoneal cavity. There was fibrinous exudate over the bile-stained, distended intestines. The liver was large, deeply jaundiced but otherwise normal. The gall bladder was empty but a stone was found at the junction of the hepatic and cystic ducts. It appeared that the infection seen in the bile passages had given rise to general peritonitis. The spleen was small and bile-stained. The stomach was distended and contained coagulated and coffee-ground material. The meninges were congested and multiple punctate haemorrhages were seen in the cerebral white matter. The other viscera were normal apart from the presence of jaundice.

It was concluded that the common bile duct had been obstructed by gall stone (probably pigment stone) causing obstructive jaundice, and secondary acute inflammation of the bile passages leading to staphylococcal peritonitis.

\section{Aetiology}

Age. The first report of gall stones in infancy is stated by Snyder, Chaffin and Oettinger (1952) to have been made in 1767. In 1899 Still reviewed 20 case reports and added three further cases in infants under the age of 9 months. The calculi in Still's patients were very small and often numerous. They resemble those described by Lightwood and Bodian (1946) in two children under 6 months of age with erythroblastosis foetalis. It was not until later that stones were observed in the foetus. Still (1899) considered it likely that the stones in some of his cases were formed during intra-uterine life and Jones (1951) reported a case associated with intra-uterine cholecystitis. Snyder et al. had, by 1952, found only two other reports of stones in the foetus, but had collected 90 cases in infancy in the world literature.

Although before puberty gall stones are commoner than cholecystitis (Ladd and Gross, 1941) they nevertheless occur infrequently (Rapoport, 1954). The commonest associated feature in this age period is the haemolysis of acholuric jaundice in the white and of sickle cell anaemia in the coloured races. Mintz, Church and Adams (1955) go so far as to say that if stones occur under the age of 40 years in a coloured patient he should be examined for sickle cell anaemia, though Weens (1945) narrows the age range, stating that stones associated with this type of anaemia are seldom seen in the first decade.

Sex. Robertson (1945) in an historical review on the subject of gall stones states that in adults over 30 years of age females are affected twice as often as males. Ulin, Nosal and Martin (1951) also found a female preponderance in gall bladder stones associated with cholecystitis in children. Forshall and Rickham (1954) reported stones in five children with abnormalities of the biliary ducts and they were all females. In general, the female proneness to gall stones seems less marked in childhood and in the present series there were five females and four males. The two cases of erythroblastosis were males, the child with portal vein changes following neonatal sepsis was a female, two of the three with acholuric jaundice were females, that with cystic duct stenosis was female and there was one of each sex of unknown cause.

Race. There is an obvious racial selection related to the incidence of the various haemolytic anaemias discussed below. But in addition Ansari (1953) points out that gall stones are rarer in India than in western Europe, England or the United States. The incidence of stones within the white races varies considerably from place to place within a geographical area as well as from one region to another. There must be dietetic and environmental factors yet unrecognized which play a part in this geographical selection.

Haemolytic Anaemia. For many years the association between gall stones and acholuric jaundice has been recognized and now sickle cell anaemia is incriminated. As might be expected the incidence of stones is greater in adult life, the Mayo Clinic figure in congenital haemolytic anaemia quoted by Mintz et al. (1955) being 70\%. Gross (1953) found gall stones in three out of six children under 14 years of age with haemolytic anaemia. 
TABLE 1

ANALYSIS OF 100 CASES OF HAEMOLYTIC ANAEMIA

\begin{tabular}{|c|c|c|c|c|c|c|c|}
\hline & & $\begin{array}{l}\text { Acholuric } \\
\text { Jaundice }\end{array}$ & $\begin{array}{l}\text { Erythro- } \\
\text { blastosis } \\
\text { Foetalis }\end{array}$ & $\begin{array}{c}\text { Atypical } \\
\text { Haemolytic } \\
\text { Anaemia }\end{array}$ & $\begin{array}{c}\text { Acute } \\
\text { (Lederer) } \\
\text { Haemolytic } \\
\text { Anaemia }\end{array}$ & Thalassaemia & $\begin{array}{c}\text { Sickle Cell } \\
\text { Anaemia }\end{array}$ \\
\hline $\begin{array}{l}\text { Number } \\
\text { Gall stones found. } \\
\text { Abdominal pain present } \\
\text { Pain referrable to gall bladder } \\
\text { Spleen not palpable } \\
\text { Splenectomy } \quad \text {.. }\end{array}$ & $\begin{array}{l}\cdots \\
\cdots \\
\cdots \\
\cdots \\
\cdots\end{array}$ & $\begin{array}{r}42 \\
3 \\
14 \\
6 \\
1 \\
31\end{array}$ & $\begin{array}{r}29 \\
2 \\
\frac{9}{9} \\
\end{array}$ & $\begin{array}{l}\frac{16}{5} \\
1 \\
2 \\
4\end{array}$ & $\begin{array}{l}\frac{6}{2} \\
1 \\
4 \\
\end{array}$ & $\frac{6}{1}$ & $\frac{1}{E}$ \\
\hline
\end{tabular}

In the present series five out of nine children had haemolytic disease. These five were found on analysis of 100 cases of haemolytic anaemia covering the period 1940-56 (Table 1).

Cholecystitis. Ladd and Gross (1941) state that in children gall stones are commoner than cholecystitis. With the control of typhoid and scarlet fevers and of upper respiratory tract infection this is probably true though study of the literature would suggest that this has not always been the case. The association between the two is accepted and cases have been reported recently by Lawler, West and Murphy (1951), Ulin et al. (1951), Dannenberg and Sarioglu (1954) and others. Lawler et al. (1951) surprisingly state that stone formation is not often a sequel of infection, yet Potter (1938) calculated that $27.9 \%$ and Ulin et al. (1951) $68 \%$ of cases of cholecystitis in children had calculi. There is agreement, however, that common bile duct stone is rare; $6 \%$ is the figure given by Ulin et al. (1951) and less than $3 \%$ by Potter (1938) and Pratt, Sauer and Gray (1951). In the presence of long-standing disease it may be difficult to decide whether the stone or the inflammation was primary. In the nine cases in this series none were regarded as being due to primary cholecystitis.

Anatomical Anomalies. Perhaps too little attention has been paid to the possibility that macroscopic or microscopic abnormalities of the bile duct system could be the primary cause of obstruction leading to stagnation and stone formation. Forshall and Rickham (1954) report four cases in which minor anatomical abnormalities were responsible, and similar findings are recorded by Bogatko and Mehlman (1947), Liège and Musac (1951) and at the Paediatric Clinical Conference (1949). Vague reference is made to such abnormalities by Lawler et al. (1951) and there are a number of other cases in which such changes might be suspected, but in which serial sections of the cystic duct were not reported. This examination was done in retrospect in two of the three cases presented here and in
Case 2 a segmental stenosis was found. In cases without other obvious aetiology this detailed histology is certainly justified and may prove rewarding. Cystic duct obstruction caused by the cystic lymph gland has been recorded on two occasions (Jones, 1951; Rankin, 1955). In one, this caused acute distension of the gall bladder and in the other gall stones and acute cholecystitis were found.

Miscellaneous Factors. The importance of dehydration in the presence of partial or complete obstruction of the biliary tract is obvious, but other mechanisms have been suggested to account for the occurrence of stones in the absence of infection or obstruction. Tesler (1946) suggests that genetic as well as constitutional factors are at work because he found gall stones in identical twins. Sodeman (1950) points out that absence of bile salts causes precipitation of cholesterol and Dannenberg and Sarioglu (1954) suggest that agglutinins may cause bile precipitation round which a stone could form. Rankin (1955), in describing acute distension of the gall bladder, suggests 'biliary dyschezia' as a cause. If such a condition exists it could obviously play a part in the production of stones.

\section{Symptoms and Diagnosis}

The classical story of right subcostal pain, the finding of tenderness and possibly enlargement of the gall bladder and finally the visualization of gall stones radiologically makes for easy diagnosis. Despite the confidence of Babbitt (1956) it is very apparent from the literature and from two of the three cases described that these symptoms and signs are not infrequently wanting. Nausea, vomiting and jaundice can be caused by other conditions, the pain is often vaguely situated and may localize in the right iliac fossa (Walker, 1951) and back and shoulder pain are rare (Ladd and Gross, 1951; Forshall and Rickham, 1954).

Jaundice as a symptom of gall bladder stones is a surprisingly frequent finding in spite of the low 
incidence of common duct obstruction (Potter, 1938). Alternative suggestions as to the mechanism of obstruction include pressure on the common duct by the gall bladder itself or hepatocellular damage.

The frequency of an impalpable spleen in haemolytic anaemia is recorded in Table 1 . Splenomegaly is a reliable sign in cases with prolonged or recurrent haemolysis and its absence might be expected in acute haemolytic episodes. Thirty-four per cent. of babies with erythroblastosis were found to have impalpable spleens. The size of the spleen is no help in the diagnosis of gall stones due to haemolytic disease.

The incidence of abdominal pain was investigated in the 100 cases of haemolytic anaemia outlined in Table 1. Of the 14 cases of acholuric jaundice with abdominal pain, in only six was the pain related to the gall bladder area. Of 16 children with atypical haemolytic anaemias and six with acute Lederer type, five and two cases respectively had pain. This was related to the gall bladder area only once in each instance. The pain may in some of these cases, as in the child with thalassaemia, be due to the immense size of the spleen but this could not have been the cause in many. It is probable that gall stones are responsible for the pains in some of the cases of long-standing haemolytic anaemia; the fact, however, that pain may occur after cholecystectomy (Weens, 1945; Mintz et al., 1955) led these authors to suggest alternative causes such as hepatic or mesenteric infarcts, splenic haemorrhages or nerve root pain due to vertebral changes. The pain can be mistaken for appendicitis (Lawler et al., 1951; Liège and Muzac, 1951; Walker, 1951); and Hirsch and Freedland (1953) found appendicitis, cholecystitis and multiple stones in the one patient. The diagnosis is more difficult when the stones are not visualized by straight radiography or cholecystography. Despite the warning of Ulin et al. (1951) recurrent hepatitis was diagnosed in my Case 1 and Bogatko and Mehlman (1947) made initial diagnoses of hepatitis and pancreatic cyst in the light of negative radiography. As in Case 1 laparotomy is the ultimate necessity in these difficult cases and most writers agree that this should not be delayed unduly. At the same time they recall to mind the risks of operation in the presence of hepatic disease. Occasionally a normally functioning gall bladder containing stones may be left in situ if the stones are considered small enough to be passed spontaneously (Babbitt, 1956).

Although it is unlikely that 'silent' stones occur as often as in adults $(50 \%$ or more are silent, Robertson, 1945; Horn, 1956) it is probable that quite a number of infants with rhesus incompatibility have small stones. It is even more likely that more of the cases of acholuric jaundice and sickle cell anaemia with or without pain have stones, especially as one of the three cases of acholuric jaundice mentioned above had entirely symptomless stones. No other record of such a case was found, though this is perhaps not so surprising in view of the earlier splenectomy now performed in this condition. Babbitt (1956) describes two cases in which fairsized radiologically positive stones remained 'silent' for some months before producing typical features.

\section{Summary and Conclusions}

During the period 1940-56, nine proved cases of gall stones have occurred in The Hospital for Sick Children, Great Ormond Street. Two were associated with erythroblastosis foetalis and three with acholuric jaundice. One was of a girl who had neonatal sepsis and later was found to have cavernomatous malformation of the portal vein and portal hypertension. The remaining three, one of segmental stenosis of the cystic duct and two of unknown aetiology, are described fully.

The diagnosis and management of these cases is described and discussed.

I wish to thank the Medical Committee of The Hospital for Sick Children for granting access to the notes of the cases reviewed and in particular to Dr. G. H. Newns for his help and advice, to Dr. Martin Bodian and his staff for their valuable assistance and special reports on Cases 1 and 2 and to Miss Wright and Miss Crawford for their secretarial help.

REFERENCES

Ansari, M. Y. (1953). Indian J. Pediat., 20, 119.

Babbitt, D. P. (1956). Amer. J. Dis, Child., 92, 5.

Bogatko, F. H. and Mehlman, J. (1947). J. Pediat., 31, 75.

Dannenberg, A. M. and Sarioglu, A. R. (1954). Amer. J. Dis. Child., 88, 350 .

Forshall, I. and Rickham, P. P. (1954). Brit. J. Surg., 42, 161

Gross, R. E. (1953). The Surgery of Infancy and Childhood, p. 531.

Hirsch, H., Ray, E. B. and Freedland, M. E. (1953). Calif. Med., 79, 318.

Horn, G. (1956). Brit. med. J., $2,732$.

Ladd, W. E. and Gross, R. E. (1941). Abdominal Surgery of Infancy and Childhood, p. 287. Philadelphia.

Lawler, R. H., West, J. W. and Murphy, R. P. (1951). Amer. J. Surg., 81, 421.

Liège, R. and Muzac (1951). Arch. franc. Pédiat., 8, 98.

Lightwood, R. and Bodian, M. (1946). Archives of Disease in Childhood, 21, 209.

Mintz, A. A., Church, G. and Adams, E. D. (1955). J. Pediat., 47, 171

Paediatric Clinical Conference (1949). J. Pediat., 34, 777.

Potter, A. H. (1938). Surg. Gynec. Obstet., 66, 604.

Pratt, G. F., Sauer, W. G. and Gray, H. K. (1951). Gastroenterology, $18,443$.

Rankin, W. (1955). Archives of Disease in Childhood, 30, 60.

Rapoport, M. (1954). In Textbook of Pediatrics, ed. Nelson, W. E. 6th ed., p. 744. Philadelphia.

Robertson, H. E. (1945). Gastroenterology, 5, 345.

$\checkmark$ Robertson, H. E. (1945). Gastroenterology, 5, 345. J. Amer. med. Ass., 149, 1645.

Sodeman, W. A. (1950). Pathologic Physiology, p. 342. PhilaStill, G. F. (1899). Trans. Path. Soc. Lond., 50, 151.

Tesler, J. (1946). Gastroenterology, 7, 685.

Ulin, A. W., Nosal, J. L. and Martin, W. L. (1951). J. Amer. med. Ass., 147, 1443.

Walker, P. A. (1951). Brit. med. J., 1, 1242.

Weens, H. S. (1945). Ann intern. Med., 22, 182. 